\title{
ANÁLISE SOBRE A MICRO-HISTÓRIA E AS SUAS PRODUÇÕES BIOGRÁFICAS A PARTIR DAS DISCUSSÕES DE GIOVANNI LEVI*
}

\author{
ANALYSIS ABOUT MICROHISTORY AND BIOGRAPHICAL PRODUCTIONS FROM \\ GIOVANNI LEVI DISCUSSIONS
}

\begin{abstract}
Resumo: Existem várias perspectivas que buscam utilizar a biografia como instrumento de conhecimento histórico. Nesse sentido, este presente artigo tem a relevância de abordar a micro-história e as suas produções biográficas tendo como a principal referência o discurso de Giovanni Levi. Partindo das ideias desse teórico, este trabalho irá apresentar brevemente a sua concepção de história, o significado da metodologia microanalítica, as suas críticas com relação à história global e a história cultural e finalmente, um estudo sobre a biografia. Portanto, esta pesquisa tem como principal objetivo de proporcionar uma análise sobre as compreensões de um dos fundadores da micro- história, mas sem a pretensão de esgotar os assuntos citados.
\end{abstract}

Palavras-chave: Micro-história; Biografia; Giovanni Levi.

\begin{abstract}
There are several perspectives that seek to use the biography as historical knowledge tool. In this sense, the present article has an importance of considering the microstory and its biographical productions having as main reference the speech of Giovanni Levi. Building on the ideas from this theory, this paper will briefly present their conception of history, the meaning of microanalytical methodology, his criticism regarding the global history and cultural history and finally, a study about the biography. Therefore, this research aims to provide an analysis of the understanding of one from the founders of microstory but without the pretension of exhausting .
\end{abstract}

Keywords: Microstory; Biography; Giovanni Levi.

\footnotetext{
*Trata-se de um artigo ampliado a partir do paper realizado para a disciplina tópicos especiais de História IIHistória e Historiografia no século XXI ministrada por Giovanni Levi e por Maíra Ines Vendrame durante o primeiro semestre de 2016, oferecida pelo Programa de Pós-Graduação em História da UNISINOS.

* Historiógrafa no município de São Leopoldo Licenciada e Mestre em História pela UNISINOS.
} 


\section{Introdução}

Este artigo apresenta, brevemente, as ideias relevantes sobre a micro história e suas abordagens apontadas por Giovanni Levi. O teórico referido, é professor de história econômica na Universidade de Ca'Foscari de Veneza e um dos fundadores da micro-história. "Foi redator e co-diretor da revista Quaderni Storici, consultor da editora Rosemberg \&Sellier (Turim) e diretor, com Carlo Ginzburg e Simona Cerutti, da coleção Microstorie da Einaudi” (ESPADA, 2006, p.228), onde apresentou seus trabalhos utilizando a microanálise e publicou suas contestações a respeito da historiografia que evidencia o tempo de longa duração e o estudo do macro. Sendo assim, este artigo pretende refletir sobre alguns aspectos da micro-história como uma das possibilidades de construção de conhecimento histórico e sobre a biografia como um instrumento de divulgação das pesquisas históricas, principalmente sob a perspectiva de Giovanni Levi.

\section{A concepção de História para Giovanni Levi}

Para Levi, a História é um conhecimento resultante de muitas interpretações, pois qualquer assunto, lugar, personagem, etc. podem resultar em explicações distintas sobre o mesmo tema. Segundo o autor, o dever do historiador é trabalhar com a complexidade na busca por fragmentos da verdade, uma vez que ela é parcial. Então, a construção do discurso histórico "não deveria ser encarado meramente em termos de escolha entre história qualitativa, individualizada, e aquela história quantitativa, cuja ambição é estabelecer leis, regularidade e comportamento coletivo formal" (LEVI, 2000, p. 152). Ou seja, a atividade do historiador também é de transmissão e por isso, tanto Ginzburg como Levi “[...] estão convencidos de que a relação que se dá entre realidade e discurso histórico passa necessariamente através do fenômeno da convicção, segundo técnicas argumentativas, e de comunicação, que buscam sobretudo persuasão que a demonstração" (SERNA, 2012, p.29). Então, para Levi escrever história é se preocupar com o trabalho em três momentos: investigação, compilação dos resultados de anos de pesquisa e depois um esforço de comunicação, tendo em vista o leitor. 
Também se deve considerar o contexto em que o leitor está inserido. Atualmente, o mundo é globalizado economicamente, porém, é fragmentado com seus nacionalismos, com as condições sociais, etc. Nesse sentido, Levi considera a micro-história uma metodologia distinta da história global, pois pondera a noção fragmentada do mundo globalizado, enquanto que aquela elimina as diferenças, exclui os pequenos efeitos. Por isso, o autor percebe a história global como um sistema que não diz nada, é uma generalização, ou seja, “[...] ignora particularidades e reconhece cognitivamente apenas o que é homogêneo e comparável” (REVEL, 2011, p.48).

Assumindo outro ponto de vista, Fragoso (2002) não sugere a ideia de abandonar o tempo largo, pois "os fenômenos sociais/experiências não consistem em processos únicos, repetem-se no tempo, sendo isto produto da 'repetição' de certas relações sociais que conformam uma dada sociedade" (FRAGOSO, 2002, p.63). Ou seja, o acontecimento que aparentemente gera transformações, na verdade pode ser apenas mais um processo dentro dos limites da estrutura segmentada e por isso, a observação macro permite distinguir as permanências e as modificações. Da mesma maneira, Koselleck argumenta que a partir das estruturas e de longa duração é possível perceber as transformações. Deste modo, a perspectiva na história global oferece a possibilidade de penetrar em alguns processos de longa duração com maior propriedade para analisa-los. Conforme Braudel, (1958 apud Revel, 2010) "Todos os andares, todos os milhares de andares, todos os esfacelamentos do tempo da história são entendidos a partir desta profundidade, desta semi-imobilidade; tudo gravita em sua volta” (REVEL, 2010, p. 436).

No entanto, os micro-historiadores acreditam que é preciso entender o acontecimento “[...] para muito além da compreensão do acontecimento como uma estrutura simplesmente temporal com um início e um final distintos, e interpretada pela narração.” (REVEL,2011, p.49) . O papel do historiador, conforme Levi, não é tirar conclusões gerais, mas colocar em evidência as diferenças, buscar coisas que não são imediatamente manifestas com problemas em larga escala. De certa maneira, a micro-história se propõe a ser uma narrativa que parte, se desenvolve e termina no particular, pois não pretende tirar conclusões gerais e por isso, é uma metodologia que envolve todas as possibilidades e reproduzem conflitos com pontos de vista distintos. Devido à complexidade, o papel do historiador para Levi é recuperar a história a partir de todas as variáveis do acontecimento, mas sem considera-la como uma cobertura de 
todo o passado de todas as localidades, de todos os indivíduos, pois a função da narrativa é apresentar, "através de um relato de fatos sólidos, o verdadeiro funcionamento de alguns aspectos da sociedade que seriam distorcidos pela generalização" (LEVI, 2000, p.153).

\section{Micro-história}

Existem diversas opiniões sobre a micro-história, como as de Peter Burke que a descreve como um tema especificamente italiano, fechado as histórias locais, ou seja, ligado à conservação e a sobrevivência das velhas e tradicionais comunidades. Ou então, como narrações históricas dos acontecimentos de pequena escala relacionados com a sexualidade e com os escândalos, com títulos sensacionalistas. Apesar das várias críticas de diversos teóricos, como Peter Burke e François Dosse, muitos historiadores tem se utilizado da microhistória para embasar suas pesquisas.

Mesmo sendo impossível buscar uma definição pronta da micro-história, Borges (2005) a definiu como um projeto "[...] que visa a reconstituir todas as cadeias de causalidade que a partir das escolhas dos indivíduos produzem as formas sociais que observamos" (BORGES,2005,p.152-153) Levi, um dos fundadores da micro-história, não se deteve a conceituar a metodologia, mas se ateve a ressaltar sobre a sua utilização porque acredita que qualquer coisa pode ser estudada com o microscópico, pois o acontecimento de pequena escala pode ser ou não parte da revolução de grandes escalas. Portanto, deixa claro que "O que se afirma é a impossibilidade de a sociedade ser tratada como um continuum homogêneo. Uma vez que ela é produto do fazer humano, [...]” (ESPADA, 2006, p. 273).

Nesse sentido, faz críticas às concepções que se utilizam do macro, como a história cultural. Segundo Levi, essa teoria teria sua gênese na crise da história social com a qual se integrou. Para o autor, a história cultural normalmente se baseia ou não em uma análise social extremamente estereotipada, através da investigação de conceitos dos quais é introduzido um repertório de acontecimentos interpretados e examinados em profundidade, mas sem uma reconceituação complexa e formal dos mecanismos sociais envolvidos. (LEVI, 2000). Além disso, argumenta que a história cultural está integrada com a história social, pois suas pesquisas partem do nível dos grupos, das quais podem considerar com proveito as representações do mundo social, com o intuito de analisar a origem das relações sociais (e culturais e políticas). Desta maneira, a história social e a cultural parecem estar se diluindo 
uma na outra, o que demonstra, conforme Burke (1992), problemas de definição (BURKE, 1992) Portanto, para Levi essa perspectiva somente incutiu a ideia de que se pode inventar um campo delimitado da ciência histórica preocupada em investigar como se manifestam o inconsciente do grupo estudado e seus significados implícitos, dos quais os produtos culturais são o resultado. Então, a história cultural não contribuiu com inovações metodológicas, pois ela identifica uma homogeneidade dos significados e representações sem levar em conta a pluralidade do grupo social, suas especificidades e as diferenciações internas que nela existem.

Enquanto isso, a micro-história evita a homogeneização buscando as diferenças e refutando a obsessão que a sociedade tem em classificar teoricamente e agrupar a partir das semelhanças. Partindo desse ponto de vista de que todos são singulares, Eduardo Grendi utiliza o conceito excepcional-normal para identificar entre dois extremos inexistentes uma realidade existente (LEVI, 1992). Desse modo, “[...] os micro-historiadores dão prioridade aos mecanismos concretos de mudança” (BORGES, 2005, p. 168), ou seja, identificam as relevâncias dentro das normas que permitiram que as pessoas se movessem no interior dos modelos e das possibilidades, conforme Levi descreve no trecho do capítulo que faz referência sobre o assunto:

Seu trabalho tem sempre se centralizado na busca de uma descrição mais realista do comportamento humano, empregando um modelo de ação e conflito do comportamento do homem no mundo que reconhece sua relativa - liberdade além, mas não fora, das limitações dos sistemas normativos prescritos e opressivos. Assim, toda ação social é vista como resultado de uma constante negociação, manipulação, escolhas e decisões do indivíduo, diante de uma realidade normativa que, embora difusa, não obstante oferece muitas possibilidades de interpretações e liberdades pessoais. (LEVI, 1992, p.135).

Sendo assim, um dos fundadores da micro- história reconhece as limitações impostas pela estratificação social, mas também considera o protagonismo dos sujeitos através da investigação da mobilidade dos indivíduos dentro das possibilidades permitidas nos sistemas normativos. Com relação à mobilidade dos sujeitos estudados como agentes nos contextos dos 
quais estão inseridos, Espada (2006) propõe o termo 'estratégia'1 por evidenciar um indivíduo que age a partir de uma "racionalidade limitada", isto é, através dos recursos permitidos de acordo com o seu lugar na trama social, em contextos nos quais sua atitude depende da interação com ações alheias. Por conseguinte, o controle sobre o seu resultado é limitado por uma perspectiva de constante incerteza (ESPADA, 2006), ao contrário da antiga sociologia que impunha classes sociais horizontalmente rígidas (LEVI, 1992). Em respeito a isso, Revel (1992) também destaca críticas às ciências sociais quando apresenta a obra de Levi:

A herança imaterial é portanto uma tentativa de decifrar a repartição local de uma história que pensávamos conhecer e que não deve ser lida apenas de cima para baixo; um esforço para colocar alguma ordem na desordem aparentemente não-essencial do cotidiano. Esse esforço, portanto, vira heroicamente as costas aos dois modelos de análise que têm prevalecido nas ciências sociais contemporâneas: ao modelo funcionalista e ao modelo estruturalista, para opor-lhes uma análise de tipo estratégico (LEVI, 1992, p.26).

No livro “A Herança Imaterial”, Levi (1992) demonstra a importância de se estudar as cadeias horizontais entre amigos e parentes do mesmo grau, ou verticais conforme as relações de clientela, pois a partir dessa pesquisa constatou que as relações determinavam os preços das terras. No entanto, "a micro-história não rejeitou a consideração de diferenciação social da mesma maneira que a antropologia interpretativa” (LEVI, 1992, 151-152). Pelo contrário, conforme demonstra o trecho retirado da mesma obra:

Cada nível social é determinado horizontalmente, e dessa forma, verticalmente. Mas todos, e cada um em seu lugar, se esforçam para encontrar uma resposta para os problemas que lhes vêm da grande história. Fazem-no com mais ou menos sucesso, com mais ou menos cartas na mão; são submetidos a limitações e solidariedades, verticais, mas também horizontais, que restringem sua capacidade de manobra e sua possibilidade de invenção. Mas procuram proteger-se dos acontecimentos e, melhor, neles se apoiar para melhorar suas chances (LEVI, 1992, p.26).

Assim, o autor mencionado evidenciou através da trajetória de um exorcista no Piemonte do século XVII que os vínculos culturais práticos são legitimados socialmente nas relações de compadrio e de clientela, porém não são legislados. Corroborando com esta ideia

\footnotetext{
${ }^{1} \mathrm{O}$ termo expressa um indivíduo que age a partir de uma "racionalidade limitada", ou seja, através dos recursos limitados que o seu lugar na trama social lhe compete, em contextos nos quais sua atitude depende da interação com ações alheias. Portanto, o controle sobre o seu resultado é limitado por uma perspectiva de constante incerteza (ESPADA, 2006, 262).
} 
em suas publicações "Gribaudi demonstra que as solidariedades podem estar baseadas, não tanto na similaridade da posição social, mas antes na similaridade da posição nos sistemas de relacionamentos". (LEVI, 1992,157). No caso, do exorcista Giovan Battista Chiesa, Levi constatou a importância das relações pessoais que são interpretadas como o valor socioeconômico mais importante, assim como o dinheiro na compra de terras.

Então, nessa obra Levi demonstra a importância de se analisar os indivíduos em 'redes'. Essa metáfora já utilizada por Barth, onde cada indivíduo pode ser visto como centro da investigação de relacionamentos (ESPADA, 2006), tornou-se uma das características da metodologia da micro-história que leva o historiador a vários questionamentos, tais como: Se todas as pessoas se relacionam entre si, qual a densidade proporcional relacional entre os indivíduos? Como se relacionam em diferentes grupos sociais? Como se preserva a identidade do grupo em transformação? Diante dessas questões, a última pergunta fez suscitar em Levi (1992) a seguinte argumentação:

Os indivíduos constantemente criam suas próprias identidades, e os próprios grupos se definem de acordo com os conflitos e solidariedades, que contudo não podem ser presumidos a priori, mas resultam das dinâmicas que são o objeto da análise (LEVI, 1992,152).

Assim sendo, temas como a imigração italiana ou relação entre o personalismo e institucionalismo na Argentina podem ser estudados com objetos inéditos através da microanálise. Têm-se como exemplo a tese de doutorado de Maíra Ines Vendrame que evidenciou através das variações de escala a possibilidade de trabalhar questões sobre honra e justiça nas regiões de colonização italiana do Rio Grande do Sul nas primeiras décadas de sua existência, assuntos que até então não haviam sido analisados por pesquisadores (VENDRAME, 2013). A partir do "interesse em aprofundar as experiências vivenciadas pelos imigrantes, tendo fio condutor a trajetória de alguns sujeitos, maximamente a do padre Antônio Sório, desde a Itália até o sul do Brasil" (VENDRAME, 2013, p.16) buscou entender as "formas de resolução dos impasses que passavam longe da intermediação do Estado" (VENDRAME, 2013, p.17).

Outro exemplo é o trabalho de Andrea Reguera que se debruçou no estudo sobre a ligação entre grupos sociais e indivíduos, a partir da análise envolvendo a relação entre personalismo e institucionalismo na Argentina meados do século XIX, tomando o caso de 
Juan Manuel de Rosas. Através de sua biografia e contextual construiu o mundo relacional do biografado. Assim sendo, propôs em seu trabalho a reflexão sobre a importância das ligações interpessoais na formação de um tecido de variações político-empresariais nos pampas da Argentina no século XIX.

Portanto, percebe-se o atual interesse pela biografia, "vindo dentro da ampla renovação historiográfica que se tem dado nas últimas décadas" (BORGES, 2005, 209) que trouxe conceitos de outras disciplinas, como por exemplo, a antropologia e das contribuições vindas da micro-história italiana, "como a redução da escala de análise para entender processos históricos amplos"(LEVI, 2015, p.30). A micro-história colocou em evidência a questão das variações de escala, demonstrando que através do "olhar microscópico" era possível construir um discurso histórico com problemas gerais, desmistificando eventuais distorções provocadas pelos estudos macro-históricos. Nesse sentido, muitos historiadores têm utilizado a micro-história para constituir um discurso histórico considerando "[...] os condicionamentos sociais do biografado, o grupo ou grupos em que atuava, enfim, todas as redes de relações pessoais que constituíam seu dia-a-dia” (BORGES, 2005, p.222).

\section{Biografia}

Desde o mundo grego antigo havia uma preocupação em descrever a história de uma vida no mundo ocidental. Percebendo essa trajetória da biografia, vários teóricos analisaram as variações sofridas por ela em diferentes períodos como T. Carlyle, J. Burckhardt, H. Taine, Madelénat, Michel Trebitsch, François Dosse, Giovanni Levi, entre outros. Porém, o que não mudou foi a tarefa complexa do historiador em utilizá-la como instrumento de divulgação do conhecimento histórico (BORGES, 2005), independentemente da teoria que esteja embasando a sua análise. Sendo assim, existem muitos desafios e possibilidades para o desenvolvimento da escrita biográfica que possui algumas peculiaridades como recurso metodológico.

Em primeiro lugar, é preciso reconhecer a diferença entre a biografia e a trajetória. Segundo Karsburg (2015), “[...] a biografia deve contemplar a totalidade da vida do indivíduo, problematizar os vários momentos da existência” (KARSBURG, 2015, p.33), enquanto que "A trajetória, por seu turno, não tem por obrigatoriedade abordar toda a vida do 
sujeito; antes, procura centrar as análises num período determinado" (KARSBURG, 2015, p.34). No entanto, tanto a biografia como o estudo da trajetória de um ou mais indivíduos demandam a reconstrução dos diferentes contextos em que estavam inseridos. A análise de fontes permite remeter os sujeitos ao seu tempo histórico e deste modo, é possível averiguar as estratégias produzidas pelos agentes envolvidos e diante delas, identificar "as relevâncias dentro das normas que permitiram que as pessoas se movessem no interior dos modelos e das possibilidades" (REVEL, 1998, p.28).

Outra característica da biografia é a diversidade de tipologias, das quais vários estudiosos se detiveram em classificá-las e defini-las de maneiras diferentes, conforme a perspectiva que adotam. (BORGES, 2005). Giovanni Levi, por exemplo, faz uma tipologia sobre a grande diversidade de biografias, distribuindo em quatro tipos: prosopografia e biografia modal, que expõe formas peculiares de comportamento de certo tempo e espaço. Um exemplo desse tipo de análise é a trajetória representativa do padre exorcista Giovanni Batista Chiesa, divulgada no livro escrito por Levi “A Herança Imaterial”. Já, a tipologia da biografia e contexto, busca tornar a pessoa "normal", reconstituindo a conjuntura em torno do indivíduo, muitas vezes preenchendo as lacunas que a falta de documentos provoca. Enquanto isso, a biografia e casos extremos propõe uma análise sobre uma pessoa não notável para a sua época, ou seja, o estudo de caso do qual o exemplo mais citado é o Menocchio, de $O$ Queijo e os vermes do historiador italiano Carlo Ginzburg. E a biografia e hermenêutica, que não tem preocupação em escrever uma biografia do tipo tradicional e se caracteriza pela alternância de perguntas e respostas dentro da comunidade em torno de um personagem (LEVI, 2001). Deste modo, nessa tipologia “[...] o que se torna significativo é o próprio ato interpretativo, o ato biográfico assumindo assim infinitos significados" (BORGES, 2005, p. 214).

Entretanto, independentemente da tipologia utilizada para embasar o estudo, a biografia é complexa no sentido de que "[...] os problemas enfrentados são semelhantes aos que precisamos encarar em qualquer trabalho de pesquisa histórica, acrescidos dos inerentes à observação específica da vida de um indivíduo; [...]” (BORGES, 2005, p.216). Conforme Levi (2001), um deles é perceber e aceitar que por trás do discurso historiográfico há um sujeito que produz "que não segue os modelos que associam uma cronologia ordenada, uma personalidade coerente e estável, ações sem inércia e decisões sem incertezas" (LEVI, 2001, 
p.169). Nesse sentido, Borges (2005) argumenta que "o mais sério desafio do historiador ao narrar uma vida é trabalhar, ao mesmo tempo, com a cronologia linear (que parece ter uma única direção) e com o percurso de vida que não é linear" (BORGES, 2005, p.224).

Apesar do desafio de divulgar o conhecimento histórico através da biografia, Levi acredita que o método biográfico se abre a todos os tipos de problemas dentro de fronteiras bem definidas, mesmo sendo temas complexos. No entanto, alerta para a necessidade de se utilizar esse recurso metodológico problematizando a relação “[...] entre normas e práticas, entre indivíduos e grupo, entre determinismo e liberdade, ou ainda entre racionalidade absoluta e racionalidade limitada" (LEVI, 2001, p.179).

Ao meu ver a biografia é por isso mesmo o campo ideal para verificar o caráter intersticial - e todavia importante- da liberdade de que dispõem os agentes e para observar como funcionam concretamente os sistemas normativos, que jamais estão isentos de contradições. Obtém-se assim uma perspectiva diferente- mas não contraditória-[...] (LEVI, 2001, p.180).

Sendo assim, esse instrumento de pesquisa se propõe a abordar implicitamente questões sobre o papel das incoerências entre as próprias normas nas sociedades estudadas, mas também as estratégias e as relações dos indivíduos dentro do grupo e fora dele. Dessa forma, a realidade histórica é avaliada reconhecendo as margens de manobra possíveis dos dominados em uma distribuição desigual do poder que podem impor aos dominantes mudanças significativas, porém que não alteram o status quo. Enfim, a partir da pesquisa detalhada das fontes que por vezes levam a investigação nas margens do documento para evidenciar especificidades negligenciadas pela historiografia (KARSBURG, 2015) podem reelaborar as análises e os conceitos relativos à estratificação e a solidariedade levando a modelos mais flexíveis pelos quais se constituem redes de relações, estratos e grupos sociais que permitem várias questões sobre as configurações sociais (LEVI, 2001).

\section{Considerações finais:}

Ao falar em concepção Histórica surgem diversas teorias e opiniões a respeito do assunto, no entanto há um consenso comum na aceitação de que "por trás do discurso 
historiográfico, há um sujeito que o produz". (BORGES, 2005, p. 220) e, portanto, "Todos nós historiadores construímos representações sobre o passado: toda História é uma construção, resultante de quem a escreve, do seu tempo e espaço, marcado por instituições e grupos”. (BORGES, 2005, p.216). Sendo assim, a construção do conhecimento histórico também é determinada pelos historiadores de acordo com a escolha do embasamento teórico e metodológico que utiliza para a sua pesquisa. Sendo assim, este artigo pretendeu discutir vários temas ligados a História, como a micro-história e os seus estudos biográficos, contudo, sem esgotar as possibilidades de debates sobre os temas. Os assuntos aqui abordados tiveram como referência principal a perspectiva de um dos fundadores da micro-história italiana, Giovanni Levi. A partir de suas ideias se buscou uma reflexão sobre a importância de se abordar as possibilidades em utilizar essa metodologia nas pesquisas históricas, especialmente nos estudos biográficos.

Nas pesquisas de biografia e de trajetórias a micro-história pode fornecer, pela redução de escala, o estudo das relações entre um ou mais indivíduos com os seus alheios, permitindo que o personagem seja visto como sujeito ativo. Os trabalhos mencionados no artigo representam a probalidade de se utilzar esse recurso metodológico, através do exame da trajetória de alguns sujeitos e pela busca de uma singularidade no indivíduo que o torna importante para a análise de sua trajetória ou parte dela. Como é o caso do exorcista Giovan Battista Chiesa, com o qual Levi (2000) constatou a importância do sistema de relacionamentos ou como Vendrame (2013), que em sua pesquisa demonstrou as formas de resolução dos impasses numa colônia de imigração italiana no Rio Grande do Sul

Enfim, independente da metodologia ou tipologia que se quer utilizar , "Como em qualquer trabalho de História, a vida do biografado terá o sentido que o historiador lhe conferir. (BORGES, p.225) E mesmo havendo distinções no gênero biografia ou trajetória, o rigor histórico deve ser aplicado a ambos, através "[..]do máximo possível de fontes (de preferência fontes de natureza diferente), que devem ser sistematicamente confrontadas (KARSBURG, 2015, p.32).

\section{Referências Bibliográficas}


BORGES, Vavy Pacheco. In: PINSKY, Carla Bassanezi. Fontes Históricas. São Paulo: Contexto, 2005, p.203-233.

FRAGOSO, João Luís Ribeiro. Afogando em nomes: temas e experiências em história econômica. Topoi, Rio de Janeiro, set. 2002, p. 41-70.

GINZBURG, Carlo. Representação: A palavra, a ideia, a coisa. In: Olhos de madeira: nove reflexões sobre a distância. São Paulo: Companhia das Letras, 2001.

GRIBAUDI, Maurizio. In: REVEL, Jacques. Jogos de escalas: a experiência da microanálise. Rio de Janeiro: Editora Fundação Getúlio Vargas, 1998, p.121-150.

KARSBURG, Alexandre de Oliveira. A micro-história e o método da microanálise na construção de trajetórias. In: VENDRAME, Maíra et al. (org.). Micro-história, trajetórias e imigração. São Leopoldo: Editora OIKOS, 2015, p.32-52.

KOSELLECK, Reinhart. Futuro passado: contribuição à semântica dos tempos históricos. Rio de Janeiro: Contraponto: Ed. PUC-Rio, 2006.

LÉVI, Giovanni. Sobre a micro-história. In: BURKE, Peter (Org.). A escrita da história. Novas perspectivas. São Paulo: UNESP, 1992, p. 133-161.

. A Herança Imaterial. Rio de Janeiro: Civilização Brasileira, 2000.

. Usos da biografia. In: AMADO, Janaína e FERREIRA, Marieta de Moraes (org.). Usos \& abusos da História Oral. 4ªed. Rio de Janeiro: Editora FGV, 2001, p.167-182.

Reflexões sobre família e parentela. In: VENDRAME, Maíra et al. (org.). Microhistória, trajetórias e imigração. São Leopoldo: Editora OIKOS, 2015, p.12-31.

LIMA, Henrique Espada Rodrigues. História social e microanálise: Eduardo Grendi. In: A micro história italiana: escalas, indícios e singularidades. Rio de Janeiro: Civilização Brasileira, 2006, p. 151-223.

PRESTES, Zoia. O rigor metodológico em pesquisa bibliográfica. In: Ensino Em Re-Vista, v. $19, \quad$ n. 2 , jul./dez. 2012, p.403-407. Disponível em: www.seer.ufu.br/index.php/emrevista/article/download/14947/8447. Acesso em 24 de julho de 2016.

REGUERA, Andrea."La Comandancia general de Juan Manuel de Rosas de la División Izquierda de la Expedición al Desierto de 1833. Lazos personales, relaciones de mando y subordinación en el proceso de ocupación territorial de la pampa bonaerense". Revista TEFROS, Vol. 14, $\quad \mathrm{N}^{\mathrm{o}}$ 1, 2016: 76-120. Disponível em: 
http://www.hum.unrc.edu.ar/ojs/index.php/tefros/article/view/408. Acesso em 25 de janeiro de 2017.

REVEL, Jacques. Microanálise e construção do social. In: REVEL, Jacques (Org.). Jogos de escalas: a experiência da microanálise. Rio de Janeiro: Editora Fundação Getúlio Vargas, 1998, p.15-38.

Micro-história, macro-história: o que as variações de escala ajudam a pensar em um mundo globalizado. Revista Brasileira de Educação, vol. 15, n. 45, set./dez. 2010, p. 434444.

ROSENTHAL, Paul-André. Construir o macro pelo micro: Frederik Barth e a "microstoria". REVEL, Jacques (Org.). Jogos de escalas: a experiência da microanálise. Rio de Janeiro : Editora Fundação Getúlio Vargas, 1998.

SERNA, Justo; PONS, Anaclet. O buraco da agulha. De que falamos quando falamos de micro-história? In: MARTINS, Maria Cristina Bohn; MOREIRA, Paulo Roberto Staudt. Uma história em escala. A micro-análise e a historiografia latino-americana. São Leopoldo: Oikos; Ed. da Unisinos, 2012, p. 15-72. (Coleção EHILA)

TOMICH, Dale. A ordem do tempo histórico: a Longue Durée e a Micro-História. Almanack, UNIFESP, n. 2, dez. 2011, p. 38-51.

VENDRAME, Maira. Ares de Vingança: redes sociais, honra familiar e práticas de justiça entre imigrantes italianos no sul do Brasil (1878-1910). Tese (Doutorado em História). Pontifícia Universidade Católica do Rio Grande do Sul, Porto Alegre, 2013. 